\title{
Factors Influencing Fixed-Route Transit Decision-Making: Exploring Differences by Disability and Community Type
}

\author{
Jordana L. Maisel and Jimin Choi \\ Center for Inclusive Design and Environmental Access, University at Buffalo \\ Molly E. Ranahan \\ Center for Inclusive Design and Environmental Access, School of Architecture and Planning, \\ University at Buffalo \\ Department of Family Medicine, Primary Care Research Institute, \\ University at Buffalo
}

\begin{abstract}
Transit agencies utilize the following complementary initiatives to encourage greater fixed-route transit usage by people with disabilities: (1) implementing more rigorous paratransit eligibility determination practices, and (2) addressing the factors that deter people with disabilities from using fixed-route transit. This research focuses on the latter and uses previously conducted survey data to determine the most important factors individuals with disabilities consider when deciding to use various transportation options, and how these factors vary by disability and community type. Findings indicate that individuals with mobility impairments consistently rated the built environment factors as more important to their transit mode decision-making than scheduling-related factors. Findings also highlight the importance of addressing complex trips when assisting riders with intellectual and cognitive disabilities. The current study also reveals that people with disabilities experience barriers differently based on where they live, suggesting the need for context sensitive interventions to support fixed-route ridership. Transit agencies should utilize this information to employ more targeted interventions to encourage greater fixedroute transit usage for individuals with disabilities.
\end{abstract}

Keywords: Public transportation, fixed-route, disabilities, paratransit, built environment, transit

(C) 2021 Jordana L. Maisel, Molly E. Ranahan, and Jimin Choi https//doi.org/10.5038/2375-0901.23.1.1 ISSN: 1077-291X | Licenced under Creative Commons License Attribution - Noncommercial 4.0 The Journal of Public Transportation is published by the Center for Urban Transportation Research at the University of South Florida 
Factors Influencing Fixed-Route Transit Decision-Making: Exploring Differences by Disability and Community Type

\section{Introduction}

Transportation access is critical for ensuring employment, citizenship, social role participation, and social interaction for people with disabilities. People with disabilities travel less frequently and rely on public transportation more frequently than the general population (Penfold et al. 2008). People with disabilities also commonly rely on paratransit even if they are able to use fixed-route services (Thatcher et al. 2016; Ranahan, Maisel, and Lenker 2018). To offset the high costs of paratransit, transit agencies encourage greater fixed-route transit use for people with disabilities by addressing the factors that deter fixed-route transit use. This paper is a secondary analysis of previously collected data and examines how sociodemographic characteristics, specifically disability and community type, affect transit mode decision-making for people with disabilities. These findings help identify more targeted interventions that transit agencies can use to support greater fixed-route transit use by individuals with disabilities.

\section{Public Transportation and People with Disabilities: A Brief Literature Review}

Millions of Americans experience transportation barriers (Rosso, Auchincloss, and Michael 2011; Syed, Gerber, and Sharp 2013; NCD 2015). These barriers are exponentially worse for people with disabilities, who have more frequent health care needs, require greater accessibility to transportation, and often have lower incomes than the general population (Syed, Gerber, and Sharp 2013). Approximately 3.6 million people with disabilities cannot leave their homes because of poor transportation access (BTS 2018). Individuals who are able to leave their homes represent $40 \%$ of the 15 million people in the United States, in both urban and rural communities, who have inadequate access to transportation (NOD 2013; NCD 2015). Many people with disabilities experience barriers to social participation, especially employment, due to poor transportation access. For example, there is an estimated employment gap of more than $41 \%$ between those with and without disabilities in the United States (Kraus 2017).

People with disabilities cite insufficient level of service and inaccessible routes to stops and stations as two of the primary public transportation barriers they experience (NCD 2015; Bezyak, Sabella, and Gattis 2017). These barriers often contribute to dependence on ADA complementary paratransit service (Golden and Weiner 2005), which provides a demand-responsive option for riders unable to use fixed-route transportation. Paratransit trips are usually curb-to-curb and point-to-point. Title II of the Americans with Disabilities Act (ADA) requires public transit authorities to maintain complementary ADA paratransit services to areas within a three-quarter-mile distance from fixed-route bus lines and rail stations. Title II also requires that the fare for the complementary ADA paratransit rides not exceed twice the amount charged to a passenger taking a comparable trip on fixed-route service (Henning 2007; Gupta et al. 2010). However, paratransit is the most expensive form of accessible transportation for transit agencies to provide (GAO 2012; Lesh 2013). The average paratransit trip costs transit agencies 3.5 times more than a fixed-route trip. By 2030, required annual funding for paratransit services is expected to grow by $\$ 3.3$ billion for operating expenses and $\$ 598$ million for capital costs (Dickens and Neff 2010).

Transit agencies experience challenges balancing the physical and economic demands of providing ADA complementary paratransit services and accessible fixed-route transit services, as well as increasing pressure to contain costs while maintaining service quality (Gupta et al. 2010). There are incentives for riders and transit agencies to shift some paratransit ridership to more effective transit services. For paratransit riders, the benefits include improved response times, flexibility and spontaneity of service routes, and enhanced community 
mobility (NCD 2015; Bezyak, Sabella, and Gattis 2017). The benefits for transit agencies include improved service and cost containment. Despite these benefits, limited formal research explores best practice strategies for encouraging able paratransit riders to use fixed-route, and the factors influencing transit mode decision-making for individuals with disabilities.

Transit agencies implement various strategies to encourage greater fixed-route use by people with disabilities. Previous research emphasizes the importance of implementing paratransit eligibility determination practices (see Weiner 1998; ESPA 2004; Rogers and Wiemiller 2006; Cross 2007; Koffman et al. 2007; Sapper, Goodwill, and Carapella 2009; Golden and Weiner 2005). Eligibility criteria, defined by laws and regulations issued by the US Department of Transportation, prevent complementary paratransit from becoming the primary transportation service for people with disabilities. Several articles and case studies describe the implementation of paratransit eligibility improvement strategies (Metro Magazine 2011a, 2011b; APTA 2011; MTM 2013; Dubost and Lee 2013). Most recently, Thatcher et al. (2016) reported best practices in paratransit eligibility determination, including: (1) using in-person interviews and functional assessments; (2) establishing and enforcing measurable and specific eligibility conditions, such as actual weather conditions; (3) developing efforts to improve passenger awareness about conditions of eligibility and other transportation options; (4) using detailed on-street assessments to detect path-of-travel barriers; (5) offering travel training on fixed-route for conditionally eligible passengers; and (6) adopting trip-by-trip eligibility and software to enforce it. However, the study did not systematically document the adoption of these strategies, nor did it explore the factors that contributed to implementation successes or challenges.

In response to these gaps, Ranahan, Maisel, and Lenker (2018) interviewed 16 transit agencies to examine the implementation of these six paratransit eligibility best practices. Findings indicated that most transit agencies in the sample incorporated multiple best practice eligibility strategies as part of department-wide changes in paratransit operations. Results also suggested that transit agencies might be able to overcome implementation challenges by recognizing departmental constraints and collaborating with other departments and outside organizations.

Previous research also examined strategies transit agencies employ to encourage greater intentional use of fixed-route service among riders. Studies about decision-making (Balog 1997; Meyers et al. 2002; Svensson 2003; Crabtree, Justiss, and Troyer 2008; Bradley and Koffman 2012) cite several factors that influence mode choice, including: (a) path of travel to and from transit stops (e.g., accessibility of pedestrian environment, distance to stops, weather); (b) fixed-route rider experiences (e.g., transit facility accessibility, concerns about lifts and securement); and (c) system navigation (e.g., transfers, unexpected situations). Although these studies documented diverse ridership characteristics, very few specifically assessed the factors that influence people with disabilities to use public transit. Thatcher et al. (2016) did identify factors influencing fixed-route transit decision-making by people with disabilities, but these findings did not explore differences by sociodemographic factors.

\section{Research Methods}

This study used previously collected data from the Transit Cooperative Research Program (TCRP) Project B-40 National Survey of People with Disabilities (NSPD) (Thatcher et al. 2016) to examine the relationship between two sociodemographic variables (disability and community type) and factors influencing fixed-route transit decision-making by people with disabilities. 


\section{Participants}

Thatcher et al. (2016) disseminated the web-based survey in 2012 to participants throughout the US disability community. Survey participants from that study were considered ineligible for this secondary analysis if they lived in a community that did not provide fixed-route service or ADA paratransit service, or if they were unaware these services existed in their community. Of the 1,889 people who completed the initial survey, 7 were from non-US participants and 69 were from individuals who did not have a disability. An additional 378 responses were excluded due to missing data $(N=378)$. Thus, the final sample for this study included responses from 1,435 US-based individuals who lived in a community that had both a fixed-route transit service and ADA complementary paratransit service.

\section{Measures}

Independent variables included disability type and community type. Disability type indicated individuals who reported having a mobility impairment, blindness or a vision impairment, an intellectual/cognitive disability, and/or a psychiatric disability. Respondents could select multiple disability categories. The survey also asked participants to describe the type of community where they lived. The five original options were later reclassified into four response groups: larger city, small city, suburban, and small town/rural communities.

The Thatcher et al. (2016) survey also assessed how people with disabilities rated the importance of 13 factors influencing fixed-route transit decision-making, measured using a five-point Likert scale ranging from 1 (not important) to 5 (very important). Respondents most frequently rated six factors as the most important in influencing their fixed-route transit usage These dependent variables naturally fell into two distinct categories: built environment (BE-1, BE-2, BE-3) and scheduling (S-1, S-2, S-3). In order of importance, these factors included:

1. BE-1: Barriers in the pedestrian environment getting to and from stops/stations

2. BE-2: Distances to or from stops/stations

3. S-1: Fixed-route service doesn't run often enough

4. S-2: Complex or multiple transfers on fixed-route service

5. S-3: Fixed-route service doesn't run at the hours I need to travel

6. BE-3: Lack of information about potential barriers I may encounter getting to/from fixed-route stops/ stations.

\section{Data Analysis}

Statistical analyses were completed using the R open source statistical software version 3.5.2 (R Core Team 2018). Descriptive statistics on sociodemographic variables and factors influencing fixed-route transit decisionmaking were computed. Nonparametric tests were adopted for different analyses because the distribution of the six factors violated the normality assumption with large negative skewedness. Nonparametric repeated measures analysis of variance (ANOVA) tests (Brunner, Domhof, and Langer 2002) were conducted to test differences in factors influencing fixed-route transit decision-making by each disability type using the R software package "nparLD" (Noguchi et al. 2012). In addition, Kruskal-Wallis rank sum tests were used to evaluate the impact of community type on each important factor that influenced fixed-route transit decision-making across disability type. This rank-based nonparametric test provided a powerful alternative to the one-way ANOVA test. All significant effects $(\mathrm{p}<.05)$ were further investigated with a rank-based method utilizing Tukey's procedure for pairwise comparisons using the R package "nparcomp" (Konietschke et al. 2015). 


\section{Results}

\section{Sample Demographics}

Table 1 summarizes selected demographic characteristics of the 1,435-person sample. The greatest number of survey respondents were from a large city (33.4\%). Of the remaining two-thirds, approximately $29.5 \%$ reported living in a small city, $23.9 \%$ in a suburb, and $13.2 \%$ in a small town/rural community. The most common disability reported was a mobility disability (MD, 56.4\%), followed by blindness or vision impairment (B/VI, 35.2\%), intellectual/cognitive disability (I/CD, 26.3\%), and psychiatric disability (PD, 13.5\%). About 30\% of respondents reported having multiple disabilities.

\section{TABLE 1.}

Demographic Characteristics of Secondary Analysis Sample

\begin{tabular}{|l|r|}
\hline \multicolumn{2}{|l|}{ Number (\%) } \\
\hline Total & $1,435(100.0)$ \\
\hline Community Type & $479(33.4)$ \\
\hline Large City & $423(29.5)$ \\
\hline Small City & $343(23.9)$ \\
\hline Suburb & $190(13.2)$ \\
\hline Small Town/Rural & \\
\hline Mobility Disability & $809(56.4)$ \\
\hline Yes & $626(43.6)$ \\
\hline No & \\
\hline Blindness or Vision Impairment & $505(35.2)$ \\
\hline Yes & $930(64.8)$ \\
\hline No & $190(13.2)$ \\
\hline Intellectual/Cognitive Disability & $1,245(86.8)$ \\
\hline Yes & $1,058(73.7)$ \\
\hline No & $194(13.5)$ \\
\hline Psychiatric Disability & $1261(86.5)$ \\
\hline Yes & \\
\hline No & \\
\hline Other Disability & \\
\hline Yes & \\
\hline No & \\
\hline
\end{tabular}

\section{Factors Impacting Fixed-Route Transit Decision-Making by Disability Type}

Figure 1 illustrates the ratings of the six important factors influencing fixed-route transit decision-making compared across disability groups. Findings show statistically significant differences across the ratings of these factors within each disability type (Table 2). For example, individuals with a mobility disability rated two built environment-related factors, barriers in the pedestrian environment and distances to or from stops/stations, 
as very important (median $=5$ ), and they rated these variables as significantly more important than some scheduling-related factors ( $\mathrm{ps}<.05$ ). Although blind and/or visually impaired individuals gave the same median rating across the factors, they rated barriers in the pedestrian environment as significantly more important than service hours and lack of information about potential pedestrian environment barriers ( $\mathrm{ps}<.05$ ). In addition, these individuals rated service frequency and complex/multiple transfers significantly more important than service hours (ps <.05). Individuals with an intellectual and/or cognitive disability rated complex/multiple transfers as very important (median $=5$ ). This factor was rated significantly more important than other built environment and scheduling-related factors (ps < .05) except for distances to or from stops/stations. Individuals with a psychiatric disability rated service frequency and service hours as very important (median $=5$ ), but they were rated as only significantly more important than one built environment-related factor, lack of information about potential pedestrian environment barriers ( $\mathrm{ps}<.05$ ).

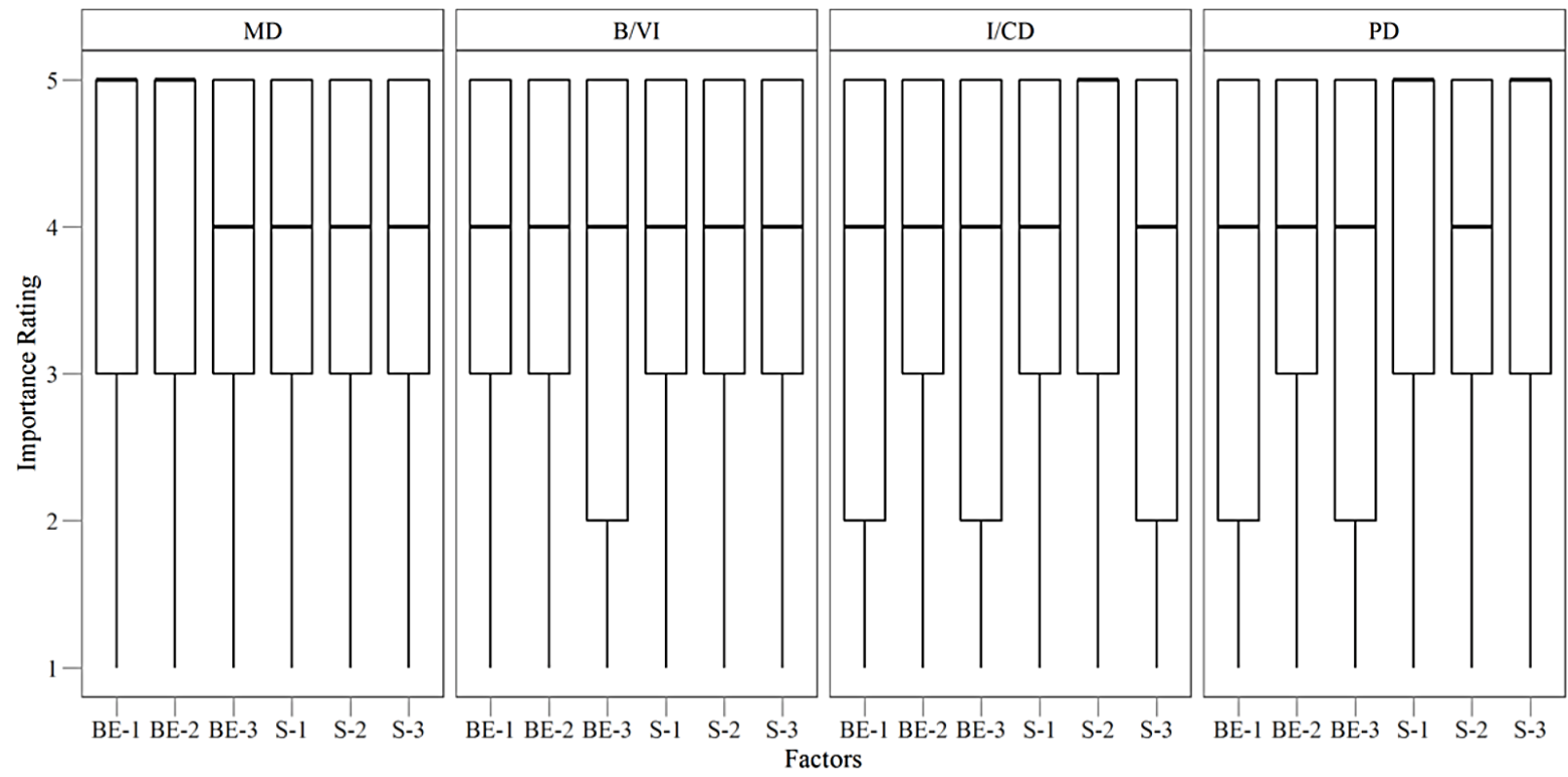

Importance Rating: 1 (not important) to 5 (very important).

MD (Mobility Disability); B/VI (Blindness or Vision Impairment); I/CD (Intellectual/Cognitive Disability); PD (Psychiatric Disability).

Thick lines indicate median value and box shows interquartile range (IQR - from the 25th to 75th percentile).

Whiskers coming out of boxes show the most extreme ratings that are within 1.5 times the IQR.

\section{FIGURE 1.}

Comparison across factors impacting fixed-route transit usage by disability type 
Table 2 summarizes the results for the significant effects $(\mathrm{p}<.05)$ and pairwise Tukey comparisons of interest $(p<.05)$. Findings are based on the nonparametric repeated measures ANOVA tests examining the factors impacting fixed-route transit usage across the four disability types.

\section{TABLE 2.}

Summary Results for Significant Effects and Pairwise Tukey Comparisons of Interest

\begin{tabular}{|c|c|c|c|c|c|}
\hline \multirow{2}{*}{$\begin{array}{l}\text { Disability } \\
\text { Type }\end{array}$} & \multirow{2}{*}{$\begin{array}{l}\text { Number of } \\
\text { Observations }\end{array}$} & \multicolumn{3}{|c|}{ ANOVA-Type Statistic } & \multirow{2}{*}{$\begin{array}{c}\text { Tukey's Pairwise } \\
\text { Comparisons }\end{array}$} \\
\hline & & $\mathrm{F}$ & df & $p$-value & \\
\hline MD & 809 & 10.17 & $3.7, \infty$ & $<.001^{* * *}$ & $\begin{array}{l}\mathrm{BE}-1>\mathrm{BE}-3^{* *}, \mathrm{~S}-1^{* *}, \mathrm{~S}-2^{*}, \\
\mathrm{~S}-3^{* * *} ; \\
\mathrm{BE}-2>\mathrm{BE}-3^{* *}\end{array}$ \\
\hline $\mathrm{B} / \mathrm{VI}$ & 505 & 5.96 & $3.5, \infty$ & $<.001^{* * *}$ & $\begin{array}{l}\mathrm{BE}-1>\mathrm{BE}-3^{*}, \mathrm{~S}-3^{*} ; \\
\mathrm{S}-1^{*}, \mathrm{~S}-2^{*}>\mathrm{S}-3\end{array}$ \\
\hline $\mathrm{I} / \mathrm{CD}$ & 377 & 7.66 & $3.2, \infty$ & $<.001^{* * *}$ & $\begin{array}{l}\mathrm{BE}-2>\mathrm{BE}-3^{*} ; \\
\mathrm{S}-2>\mathrm{BE}-1^{*}, \mathrm{BE}-3^{* * *}, \mathrm{~S}-1^{*}, \\
\mathrm{~S}-3^{*}\end{array}$ \\
\hline PD & 194 & 6.39 & $3.5, \infty$ & $<.001^{* * *}$ & $\begin{array}{l}\mathrm{BE}-2^{*}, \mathrm{~S}-1^{* *}, \mathrm{~S}-2^{*}, \mathrm{~S}-3^{* * *} \\
>\mathrm{BE}-3\end{array}$ \\
\hline
\end{tabular}

\section{Factors Impacting Fixed-Route Transit Decision-Making by Disability and Community Type}

Kruskal-Wallis tests show significant differences in scheduling-related factors, including service frequency $[\mathrm{X} 2(3)=7.96, \mathrm{p}=.047]$, complex/multiple transfers $[\mathrm{X} 2(3)=7.96, \mathrm{p}=.047]$, and service hours $[\mathrm{X} 2(3)=13.91$, $\mathrm{p}=.003]$, across community types for individuals with a mobility disability (see Table 3 ). Individuals with a mobility disability living in small towns/rural communities rated service frequency as significantly more important than individuals with a mobility disability living in suburban communities $(p<.05)$. Individuals with a mobility disability living in small cities rated complex/multiple transfers as significantly more important than this group of individuals living in small towns/rural communities $(p<.05)$. Additionally, individuals with a mobility disability living in small cities and small towns/rural communities rated service hours as significantly more important than individuals living in large cities ( $p s<.05$ ). 
TABLE 3.

Relationship between Community Type and Factors Influencing Fixed-Route Transit Usage

\begin{tabular}{|c|c|c|c|c|}
\hline \multirow[t]{2}{*}{ Disability Type } & \multirow[t]{2}{*}{$\begin{array}{l}\text { Influencing } \\
\text { Factor }\end{array}$} & \multicolumn{2}{|c|}{$\begin{array}{l}\text { Kruskal-Wallis Rank Sum } \\
\text { Statistic }\end{array}$} & \multirow[t]{2}{*}{$\begin{array}{l}\text { Tukey's Pairwise } \\
\text { Comparisons }\end{array}$} \\
\hline & & $x^{2}(3)$ & $p$-value & \\
\hline \multirow[t]{6}{*}{$M D$} & $\mathrm{BE}-1$ & 1.08 & .782 & \\
\hline & $B E-2$ & 3.11 & .374 & \\
\hline & $B E-3$ & 0.89 & .827 & \\
\hline & $S-1$ & 7.96 & $.047 \quad *$ & $d>c^{*}$ \\
\hline & $S-2$ & 7.96 & $.047 *$ & $b>d^{*}$ \\
\hline & $\mathrm{S}-3$ & 13.91 & $.003 \quad * *$ & $b^{*}, d^{* *}>a$ \\
\hline \multirow[t]{6}{*}{$\mathrm{B} / \mathrm{VI}$} & BE-1 & 0.20 & .977 & \\
\hline & $B E-2$ & 3.38 & .336 & \\
\hline & $B E-3$ & 2.34 & .505 & \\
\hline & $\mathrm{S}-1$ & 17.03 & $<.001^{* * *}$ & $\mathrm{~b}>\mathrm{a}^{*}, \mathrm{c}^{* * *} ; \mathrm{d}>\mathrm{c}^{*}$ \\
\hline & $S-2$ & 8.99 & $.029 \quad *$ & $a^{*}, b^{*}>d$ \\
\hline & $\mathrm{S}-3$ & 17.41 & $<.001^{* * *}$ & $\mathrm{~b}<\mathrm{a}^{* * *}$ \\
\hline \multirow[t]{6}{*}{$I / C D$} & BE-1 & 6.45 & .092 & \\
\hline & $\mathrm{BE}-2$ & 1.64 & .650 & \\
\hline & $\mathrm{BE}-3$ & 3.14 & .371 & \\
\hline & S-1 & 6.36 & .095 & \\
\hline & $\mathrm{S}-2$ & 6.76 & .080 & \\
\hline & $\mathrm{S}-3$ & 6.75 & .080 & \\
\hline \multirow[t]{6}{*}{ PD } & BE-1 & 3.96 & .266 & \\
\hline & $\mathrm{BE}-2$ & 0.29 & .962 & \\
\hline & $\mathrm{BE}-3$ & 1.64 & .650 & \\
\hline & $S-1$ & 1.43 & .699 & \\
\hline & $\mathrm{S}-2$ & 5.04 & .169 & \\
\hline & $\mathrm{S}-3$ & 2.68 & .443 & \\
\hline
\end{tabular}

(a) Large City; (b) Small City; (c) Suburb; (d) Small Town/Rural

Findings also show statistically significant differences in the three scheduling-related factors, including service frequency $[X 2(3)=17.03, p=.001]$, complex/multiple transfers $[X 2(3)=8.99, p=.029]$, and service hours $[X 2(3)=17.41, p=.001]$, across community types for blind and/or visually impaired individuals. This group of individuals living in small cities and small towns/rural communities rated service frequency as significantly more important than individuals who were blind and/or visually impaired living in suburban communities ( $\mathrm{ps}<.05$ ). This group of individuals living in small cities also rated service frequency as significantly more important than individuals living in large cities $(\mathrm{p}<.05)$. Blind and/or visually impaired individuals living in large and small cities rated complex/multiple transfers as significantly more important than this group of individuals living in small 
towns/rural communities (ps <.05). Blind and/or visually impaired individuals living in small cities rated service hours as significantly more important than this group of individuals living in large cities $(p<.001)$. For individuals with an intellectual and/or cognitive disability and with a psychiatric disability, there were no statistically significant differences across community type for built environment and scheduling-related factors.

\section{Discussion}

While some research examines transit mode decision-making for the general population, fewer studies specifically focus on individuals with disabilities. The current study addressed this knowledge gap by using previously collected survey data to further investigate the factors and characteristics that impact fixed-route transit decision-making for individuals with disabilities. Findings indicate that personal and contextual characteristics are critical to transit-related decision-making and may guide transit agencies and municipalities on how to improve the built environment and service delivery to increase fixed-route transit for people with disabilities.

Respondents with mobility impairments consistently rated the built environment factors (i.e., path of travel issues, including built environment barriers and distances to transit stops) as more important to their transit mode decision-making than scheduling-related factors. In the past, transit providers often addressed built environment barriers by making bus stop improvements. More recently, transit agencies and municipalities have become focused on creating streetscapes that improve the first mile/last mile (i.e., the route between an individual's origin/destination and the nearest transit service) and that support diverse transportation modes and users. Recent strategies employed to improve the first mile/last mile include passing Complete Streets policies, developing design guidelines for transit agencies and public works departments, utilizing GIS (geographic information system) data to inventory and assess environmental conditions, and funding improvements for transit stops and adjacent sidewalks with community development grants (LaBonty and Beveridge 2003; ESPA 2007; KFH Group 2005 and 2008; Wu et al. 2010; Smart Growth America 2018).

Findings also highlight the importance of addressing complex trips when assisting riders with intellectual and cognitive disabilities. This suggests the need to integrate personalized information, including individual needs and previous trip experiences, when developing travel training and trip planning programs for these individuals. Technology enhancements could provide real-time updates about built environment conditions and improvements. For example, a team of researchers at the University of Washington and Maryland is seeking to transform how sidewalk accessibility data is collected and visualized using a combination of crowdsourcing and machine learning. Project Sidewalk (http://sidewalk.umiacs.umd.edu/) is a new online tool that enables anyone-from motivated citizens to government workers - to virtually walk through cities to locate, label, and assess sidewalks. User-contributed labels help create new accessibility-friendly mapping tools (e.g., route planners, map visualizations) to train machine learning algorithms to semi-automatically assess cities in the future, and to create better transparency about city accessibility.

The current study also reveals that people with disabilities experience barriers differently based on where they live, suggesting the need for context sensitive interventions to support fixed-route ridership. Issues with fixed-route scheduling posed greater challenges for individuals living in small cities and small towns/ rural communities, especially for those with mobility impairments and/or visual impairment/blindness. To support increased fixed-route transit use by people with disabilities in these regions, transit agencies may consider implementing flexible transit delivery services. These innovative services include transportation network companies (TNCs) such as Uber or Lyft, car share services (e.g., Zipcar), or microtransit (i.e., privately 
operated, dynamically routed or crowdsourced transit service). Increased utilization of shared modes can grow ridership in public transit, reduce car ownership, and reduce the cost of transportation overall (Feigon and Murphy 2016; Polzin 2018). Providing flexible transit services can increase the level of service, reduce dependency on paratransit, and overcome first mile/last mile challenges by transporting riders with disabilities to fixed-route stops and stations (Buehler 2018; Watkins 2018). Consumers have shown support and even a preference for these new mobility options (Westervelt, Schank, and Huang 2017).

This study had several principal limitations. First, it was limited to results from a previously conducted survey in which the authors had no input in the question development or sample recruitment. Thus, the current analysis could only explore the relationship between fixed-route usage and community and disability types. Second, the initial study only used a perceived measure for community type and did not ask about individuals' transit usage. Therefore, the authors were unable to explain some relationships between variables. For example, perhaps individuals with mobility impairments living in small towns/ rural communities rated service frequency as more important than individuals living in suburbs because individuals in suburbs use personal vehicles more frequently for transportation and therefore do not care as much about fixed-route scheduling. Future research should examine how other variables (e.g., gender, age, race/ethnicity, transit mode usage) affect fixed-route decision-making as it relates to individuals with disabilities, as well as use zip codes to define community type. Third, survey respondents may have felt reluctant to disclose attributes of their transit usage and personal transit experiences that could be construed negatively, which is a risk with any self-reflective survey process. Future research could also explore perspectives from riders when solutions (e.g., travel training, trip planning services, and pedestrian infrastructure improvements) are implemented to describe and define the impact on decision-making and ridership. For example, such research could seek to understand how integrating microtransit/TNCs in transit service addresses user needs, particularly in rural and underserved communities.

\section{Conclusions}

This is one of only a few studies to report on the factors deterring fixed-route transit decision-making by individuals with disabilities. Factors related to the built environment and fixed-route scheduling were the greatest deterrents to fixed-route transit decisions by individuals with disabilities and these results significantly differed based on disability and community type. These findings highlight the need to develop more targeted interventions that resource-constrained transit agencies can efficiently deploy to encourage greater fixed-route use. Emerging technological innovations might serve as useful tools to minimize some of the reported deterrents. For example, transit agencies might integrate TNCs or microtransit to help improve level of service, real-time information about built environment barriers might help individuals with mobility impairments with route planning, and personalized travel training might benefit individuals with intellectual and cognitive disabilities. These findings also highlight the need for future research to explore additional factors that might discourage and/or facilitate fixed-route transit decision-making. The capacity to offer detailed recommendations enables transit agencies to make evidence-based decisions to encourage individuals with disabilities to use fixed-route, the more affordable and sustainable transportation mode. 


\section{References}

APTA (American Public Transportation Association). 2011. "Valley Metro Opens Mobility Center." Passenger Transport.

Balog, J. N. 1997. Guidebook for Attracting Paratransit Patrons to Fixed-Route Services. TCRP Report 24, Transportation Research Board, National Research Council. Washington, DC: National Academy Press.

Bezyak, J. L., S. A. Sabella, and R. H. Gattis. 2017. "Public Transportation: An Investigation of Barriers for People with Disabilities." Journal of Disability Policy Studies 28 (1): 52-60. doi:10.1177/1044207317702070.

Bradley, M. A., and D. Koffman. 2012. Improving ADA Paratransit Demand Estimation: Regional Modeling. TCRP Report 158, Transportation Research Board. Washington, DC: The National Academies Press. doi:10.17226/22720.

Brunner, E., S. Domhof, and F. Langer. 2002. Nonparametric Analysis of Longitudinal Data in Factorial Experiments. New York: J. Wiley.

BTS (Bureau of Transportation Statistics). 2018. Travel Patterns of American Adults with Disabilities. Washington, DC: US Department of Transportation. https://www.bts.gov/travel-patterns-with-disabilities.

Buehler, R. 2018. "Can Public Transportation Compete with Automated and Connected Cars?" Journal of Public Transportation 21 (1): 7-18. doi:10.5038/2375-0901.21.1.2.

Crabtree, J., M. Justiss, and J. Troyer. 2008. "Characteristics and Environmental Factors of Paratransit Applicants: A Step Toward Understanding the Person-Environment Dynamic and Customer Satisfaction." Presentation at 2008 Transportation Research Board 87th Annual Meeting, Washington, DC.

Cross, D. 2007. "ADA Paratransit Eligibility Models: Comparing the Options." In Proceedings of the 2006 Bus \& Paratransit Conference. Washington, DC: American Public Transportation Association.

Dubost, T., and D. Lee. 2013. "SamTrans Paratransit Eligibility Assessment Centers Building Strong Foundations for Eligibility Determinations." Presentation at 2013 APTA Bus and Paratransit Conference, Indianapolis.

Dickens, M., and J. Neff. 2010. 2010 Public Transportation Fact Book. Washington, DC: American Public Transportation Association.

ESPA (Easter Seals Project ACTION). 2004. ADA Complementary Paratransit: A Decade of Innovation. Washington, DC.

ESPA (Easter Seals Project ACTION). 2007. Toolkit for the Assessment of Bus Stop Accessibility and Safety. Washington, DC.

Feigon, S., and C. Murphy. 2016. Shared Mobility and the Transformation of Public Transit. TCRP Research Report 188, Transportation Research Board. Washington, DC: The National Academies Press. doi:10.17226/23578.

GAO (Government Accountability Office). 2012. ADA Paratransit Services: Demand Has Increased, but Little is Known about Compliance. GAO-13-17 Report to the Committee on Banking, Housing, and Urban Affairs, U.S. Senate. Washington, DC: US Government Accountability Office. http://www.gao.gov/products/GAO13-17. 
Factors Influencing Fixed-Route Transit Decision-Making: Exploring Differences by Disability and Community Type

Golden, M., and Weiner, R. 2005. The Current State of Transportation for People with Disabilities in the United States. National Council on Disability, Washington, DC. https://ncd.gov/publications/2005/current-statetransportation-people-disabilities-united-states.

Gupta, D., H-W. Chen, L. A. Miller, and F. Surya. 2010. "Improving the Efficiency of Demand-Responsive Paratransit Services." Transportation Research Part A: Policy and Practice 44 (4): 201-17.

Henning, A. 2007. Public Transportation Providers' Obligations under the Americans with Disabilities Act. Order Code RS22676, Congressional Research Service Report for Congress. https://www.everycrsreport.com/ files/20070611_RS22676_357f3a6f737bd0f8616a51dbeacddec48a3369a3.pdf.

KFH Group, Inc. 2005. Montgomery County Bus Stop Facility Inventory and Assessment, Final Report. Prepared for Montgomery County, MD.

KFH Group, Inc. 2008. Accessible Pathways Analysis for the Washington Metropolitan Area Transit Authority's MetroAccess Customers. Prepared for the Washington Metropolitan Area Transit Authority and the Metropolitan Washington Council of Governments.

Koffman, D., D. Lewis, D. Chia, J. Burkhardt, and M. Bradley. 2007. Improving ADA Complementary Paratransit Demand Estimation. TCRP Report 119, Transportation Research Board. Washington, DC: The National Academies Press. doi:10.17226/23146.

Konietschke, F., M. Placzek, F. Schaarschmidt, and L. A. Hothorn. 2015. "nparcomp: An R Software Package for Nonparametric Multiple Comparisons and Simultaneous Confidence Intervals." Journal of Statistical Software 64 (9): 1-17. doi:10.18637/jss.v064.i09.

Kraus, L. 2017. 2016 Disability Statistics Annual Report. Institute on Disability/UCED. Durham, NH: University of New Hampshire.

LaBonty, G., and C. Beveridge. 2003. "Increasing Accessibility in Communities through the Community Development Block Grant Program." Presentation at the 2003 APTA Bus and Paratransit Conference, Milwaukee, WI.

Lesh, M. C. 2013. "Innovative Concepts in First-Last Mile Connections to Public Transportation." In Urban Public Transportation Systems 2013: Proceedings of the Third International Conference on Urban Public Transportation Systems, edited by S. Jones, 63-74. Reston, VA: American Society of Civil Engineers.

Metro Magazine. 2011a. "Valley Metro Unveils Mobility Center.” Metro Magazine. https://www.metro-magazine. com/10024702/valley-metro-unveils-mobility-center.

Metro Magazine. 2011b. "Valley Metro Mobility Center Wins Innovation Award.” Metro Magazine. https://www. metro-magazine.com/10024424/valley-metro-mobility-center-wins-innovation-award.

Meyers, A. R., J. J. Anderson, D. R. Miller, K. Shipp, and H. Hoenig. 2002. "Barriers, Facilitators, and Access for Wheelchair Users: Substantive and Methodologic Lessons from a Pilot Study of Environmental Effects." Social Science \& Medicine 55 (8): 1435-46. doi:10.1016/s0277-9536(01)00269-6.

MTM. 2011. "Assessments for Tri-Met: Tri-County Metropolitan Transportation District of Oregon." Case study. http://www.mtm-inc.net/wp-content/uploads/2013/01/Assessment-Trimet-Case-Study.pdf.

NCD (National Council on Disability). 2015. Transportation Update: Where We've Gone and What We've Learned. Washington, DC: National Council on Disability. 
NOD (National Organization on Disability). 2013. "Transportation Resources." http://www.nod.org/disability_ resources/transportation_resources/.

Noguchi, K., Y. R. Gel, E. Brunner, and F. Konietschke. 2012. "nparLD: An R Software Package for the Nonparametric Analysis of Longitudinal Data in Factorial Experiments." Journal of Statistical Software 50 (12): 1-23. doi:10.18637/jss.v050.i12.

Penfold, C., N. Cleghorn, C. Creegan, H. Neil, and S. Webster. 2008. Travel Behaviour, Experiences and Aspirations of Disabled People. Department for Transport, London, England.

Polzin, S. E. 2018. "Just Around the Corner: The Future of US Public Transportation." Journal of Public Transportation 21 (1): 43-52.

Ranahan, M. E., J. Maisel, and J. A. Lenker. 2018. "How Transit Agencies Implement Best Practice Strategies in Complementary ADA Paratransit Eligibility." Journal of Public Transportation 21 (2): 73-85.

R Core Team. 2018. "R: A Language and Environment for Statistical Computing." Vienna, Austria: R Foundation for Statistical Computing. Available online at https://www.R-project.org/.

Rogers, E., and D. Wiemiller. 2006. "Sustainable ADA Compliance: Meeting Paratransit Demand Through Growth Management Strategies." Presentation at the 2006 APTA Bus and Paratransit Conference, Orange County, CA.

Rosso, A. L., A. H. Auchincloss, and Y. L. Michael. 2011. "The Urban Built Environment and Mobility in Older Adults: A Comprehensive Review." Journal of Aging Research 2011. doi:10.4061/2011/816106.

Sapper, D., J. A. Goodwill, and H. Carapella. 2009. Impacts of More Rigorous ADA Paratransit Eligibility Assessments on Riders with Disabilities. Revised Final Draft Report No. BD549-44, prepared by National Center for Transit Research for Florida Department of Transportation.

Smart Growth America. 2018. “National Complete Streets Coalition.” https://smartgrowthamerica.org/program/ national-complete-streets-coalition/.

Svensson, H. 2013. “The Public Transport Preferences of Elderly People: A Study Related to Individual Capacity and Environmental Stress in Service Route Traffic and Other Systems." PhD diss., Lund University.

Syed, S. T., B. S. Gerber, and L. K. Sharp. 2013. "Traveling Towards Disease: Transportation Barriers to Health Care Access." Journal of Community Health 38 (5): 976-93. doi:10.1007/s10900-013-9681-1.

Thatcher, R., C. Ferris, D. Chia, J. Purdy, B. Ellis, B. Hamby, J. Quan, and M. Golden. 2016. Strategy Guide to Enable and Promote the Use of Fixed-Route Transit by People with Disabilities. TCRP Report 163, Transportation Research Board. Washington, DC: National Academy of Sciences. https://nacto.org/wp-content/ uploads/2016/05/2-9_Thatcher-et-al-Strategy-Guide-to-Enable-and-Promote-the-Use-of-Fixed-RouteTransit-by-People-with-Disabilities-TCRP-Report-163_2013.pdf.

Watkins, K. 2018. "Does the Future of Mobility Depend on Public Transportation?" Journal of Public Transportation 21 (1): 53-59. doi:10.5038/2375-0901.21.1.6.

Weiner, R. 1998. ADA Paratransit Eligibility Certification Practices. TCRP Synthesis 30, Transportation Research Board. Washington, DC: National Academy Press.

Westervelt, M., J. Schank, and E. Huang. 2017. "Partnerships with Technology-Enabled Mobility Companies: Lessons Learned." Transportation Research Record: Journal of the Transportation Research Board 2649 (1): 106-112. doi:10.3141/2649-12. 
Factors Influencing Fixed-Route Transit Decision-Making: Exploring Differences by Disability and Community Type

Wu, W., A. Gan, F. Cevallos, D. L. Shen, and M. Hadi. 2010. "A GIS-Aided Decision-Making Process for Selecting Bus Stops for ADA Improvements." Presentation at the Transportation Research Board 89th Annual Meeting, Washington, DC.

\section{About the Authors}

Jordana L. Maisel, PhD (jlmaisel@buffalo.edu), is the director of research at the Center for Inclusive Design and Environmental Access in the School of Architecture and Planning at the University at Buffalo.

Molly E. Ranahan, PhD (ranahan@buffalo.edu), is an NRSA Research Postdoctoral Fellow for the Primary Care Research Institute and research assistant professor in the Departments of Family Medicine and Urban Planning at the University at Buffalo. She worked as a post-doc for the Center for Inclusive Design and Environmental Access.

Jimin Choi (jchoi32@buffalo.edu) is a graduate assistant at the Center for Inclusive Design and Environment Access and an urban planning PhD candidate in the School of Architecture and Planning at the University at Buffalo. 
Factors Influencing Fixed-Route Transit Decision-Making: Exploring Differences by Disability and Community Type 